\title{
Analysis and Testing of Load Characteristics for Rotary-Percussive Drilling of Lunar Rock Simulant with a Lunar Regolith Coring Bit
}

\author{
Peng Li, ${ }^{1,2}$ Hui Zhang, ${ }^{1}$ Shengyuan Jiang, ${ }^{1}$ and Weiwei Zhang ${ }^{1}$ \\ ${ }^{1}$ State Key Laboratory of Robotics and System, Harbin Institute of Technology (HIT), Harbin 150001, China \\ ${ }^{2}$ Mechanical Engineering College, Beihua University, Jilin 132022, China \\ Correspondence should be addressed to Peng Li; lemmber@163.com and Shengyuan Jiang; jiangshy@hit.edu.cn
}

Received 9 January 2017; Accepted 10 April 2017; Published 30 April 2017

Academic Editor: Longjun Dong

Copyright (C) 2017 Peng Li et al. This is an open access article distributed under the Creative Commons Attribution License, which permits unrestricted use, distribution, and reproduction in any medium, provided the original work is properly cited.

Based on an optimized lunar regolith coring bit (LRCB) configuration, the load characteristics of rotary-percussive drilling of lunar rock simulant in a laboratory environment are analyzed to determine the effects of the drilling parameters (the rotational velocity, the penetration rate, and the percussion frequency) on the drilling load. The process of rotary drilling into lunar rock using an LRCB is modeled as an interaction between an elemental blade and the rock. The rock's fracture mechanism during different stages of the percussive mechanism is analyzed to create a load forecasting model for the cutting and percussive fracturing of rock using an elemental blade. Finally, a model of the load on the LRCB is obtained from the analytic equation for the bit's cutting blade distribution; experimental verification of the rotary-impact load characteristics for lunar rock simulant with different parameters is performed. The results show that the penetrations per revolution (PPR) are the primary parameter influencing the drilling load. When the PPR are fixed, increasing the percussion frequency reduces the drilling load on the rock. Additionally, the variation pattern of the drilling load of the bit is in agreement with that predicted by the theoretical model. This provides a research basis for subsequent optimization of the drilling procedure and online recognition of the drilling process.

\section{Introduction}

During the sampling and exploration of extraterrestrial celestial bodies, humans normally employ rotary-percussive drilling to improve drilling efficiency to obtain pristine samples from a celestial body, reveal the origin and evolution of the celestial body, explore the possibility of extraterrestrial life, and effectively explore and properly use space resources $[1,2]$. The former Soviet Union's "Luna" series of unmanned lunar sampling missions, the United States "Apollo" series of sampling projects, which included a manned moon landing, and the "Curiosity" Mars exploration mission all employed percussion-assisted rotary drilling to ensure reliable sampling during exploration [3-6]. In the near future, China will complete an unmanned lunar surface sampling and return mission, that is, the "Change project," which will involve collecting soil samples from the lunar surface and $2 \mathrm{~m}$ below it using drill sampling $[7,8]$. When the drilling process is blocked by a large chunk of lunar rock, percussion will be used to improve the bit's ability to fracture rock. Therefore, when the drill's configuration is determined, the ability to adjust the drilling parameters to achieve the desired drilling performance is necessary to guarantee reliable lunar surface sampling.

When the former Soviet Union conducted the Luna24 unmanned autonomous sampling mission on the lunar surface, the experience of the Luna-16/20 drilling/sampling mission was drawn upon, and a percussion function was included in the drilling machine. During the actual lunar surface sampling, the drill's alarm was triggered due to an excessive drilling load. After percussion was enabled, the drilling load decreased to a certain extent, and finally, a lunar soil sample was collected successfully and sent to Earth $[9,10]$. Recently, many researchers have conducted extensive research on rock fracture via drilling tool percussion. Among them, Jalali and Zare Naghadehi conducted an experimental 
study of excavation and percussion of rock using a disc cutter tooth in a tunnel excavating machine. The result showed that the sample excavation efficiency of the disc cutter tooth improved significantly under the combined effect of cutting and percussion. Additionally, the percussion load effectively improved the penetration rate of the simulated tunnel excavating machine [11]. Hashiba et al. conducted an experimental study of a single percussion rock penetration process via button bits and modified the obtained loadpenetration depth curve using numerical simulation [12]. Based on the fracture criteria for viscoplastic rock, Saksala et al. conducted a simulation analysis and an experimental study of the percussive drilling of granite via a specially designed triple-button bit. The results showed that the rock fractured when the percussion velocity was ascending. Additionally, lateral compressive fracture occurred between adjacent buttons [13-15]. Furthermore, based on the Rayleigh-Love model and a one-dimensional viscoelastic model, Tian et al. derived an equation for the axial vibration of a drill string during oil exploration and verified it experimentally. The results showed that the length of the drill string is inversely proportional to the damping at the bottom of the bore. When the string was shorter, the effect of horizontal inertia on the dynamic rigidity of the drill string was more significant [16].

Besides, acoustic emission (AE) techniques have always been adopted in identifications of microseismic source (MS) locations. Dong and Li have proposed an innovative MS/AE source location method without the need for premeasured PS wave velocities, and this method greatly weakens the influence of the big error derived from the change of the wave velocities and propagation traces [17]. Then, he applies three nonlinear methodologies (such as random forests, support vector machines, and naive Bayes classifier) to discriminate between 20 earthquakes and 27 nuclear explosions. And based on the leave-one-out cross-validation, ROC curve, and test accuracy, random forests method clearly shows the best predictive power [18]. Recently, Dong et al. investigate the typical characters of seismic parameters between events and blasts using the datasets of three mines in Canada and Australia, and 7 parameters are extracted as discriminant indicators to establish discriminant models using the logistic regression method. The classified accuracy of training samples, test samples, and cross-validated results have demonstrated that the discriminant models with good discriminant performance are effective and efficient methods to identify the blasts from events in real-time [19]. These methodologies provide an effective way to quantify the process of rock fragmentation which are not easy to observe in rock impacting or cutting process.

In 2014, the Research Center of Aerospace Mechanism and Control (RCAMC) at Harbin University of Technology successfully designed a lunar regolith coring bit (LRCB) that exhibited excellent drilling performance in tasks such as continuous chip removal without an auxiliary medium and rock blockage breakthrough with a limited ability to drill. Compared with other geological drill bits and planetary sampling bits, it has advantages, such as a low load per unit area, for fracturing rocks $[20,21]$. In this paper, based on an optimized LRCB configuration and the Mohr-Coulomb criterion, a model of cutting and percussive fracture for lunar rock simulant is created and expanded to the rotarypercussive drilling process to analyze the load characteristics of rotary-percussive drilling of lunar rock simulant with a coring bit. The effect of the impact load on the rock's fracture load for different drilling parameters is determined; this provides a basis for optimizing the drilling parameters for lunar surface drilling and sampling.

The structure of this paper is as follows: Section 2 mainly introduces the background of previous research, that is, the LRCB configuration and the model for the load during rotary drilling of lunar rock simulant; Section 3 describes how the interaction between the LRCB and lunar rock simulant during rotary percussion is modeled; Section 4 provides experimental verification of the rotary-percussive drilling load for lunar rock simulant, and Section 5 is the conclusion.

\section{LRCB Configuration and Drilling Load Analysis}

2.1. LRCB Configuration Parameters. Based on requirements of sampling deep lunar soil, the LRCB should support the following functions: (i) ensuring smooth lunar soil chip removal without an auxiliary chip removal medium; (ii) specifying the coring rate of the lunar soil sample and ensuring the ability to collect original information; and (iii) being able to break lunar rock with less than grade-VI drillability without exceeding the drilling load limit [22]. Therefore, the RCAMC team developed the LRCB shown in Figure 1, which employs inner and outer rows of sharp cutting blades (SCBs) (i.e., dual primary cutting blades) to increase the stability of the drilling system in the initial stage of lunar rock drilling. Laboratorial tests showed that this bit excels at coring lunar soil and removing chips and has excellent lunar rock drilling load characteristics. The detailed configuration parameters of the LRCB are listed in Table 1.

2.2. Analysis of the Drilling Load of the LRCB. The LRCB's configuration parameters are abstracted as an analytic geometrical model, which is shown in Figure 2. The relationships of the torque on bit (TOB) and the weight on bit (WOB) to the cutting load of the elemental blade are shown in

$$
\begin{aligned}
T_{\mathrm{TOB}} & =\sum_{k=1}^{2} \sum_{i=1}^{2} \Delta F_{l i \_k} \cdot \sqrt{x_{b m i \_k}^{2}+y_{b m i \_k}^{2}}, \\
F_{\mathrm{WOB}} & =\sum_{k=1}^{2} \sum_{i=1}^{2} \Delta F_{n i \_k},
\end{aligned}
$$

where $x_{b m i-k}$ is coordinate of the midpoint of the $i$ th elemental blade at the $k$ th row of SCBs on the I axis; $y_{b m i-k}$ is coordinate of the midpoint of the $i$ th elemental blade at the $k$ th row of SCBs on the Kaxis; $\Delta F_{l i-k}$ is cutting force of the $i$ th elemental blade at the $k$ th row of SCBs along the $\mathbf{l}$ axis; and $\Delta F_{n i \_k}$ is cutting pressure of the $n$th elemental blade at the $k$ th row of SCBs along the $\mathbf{n}$ axis.

In (1), $\Delta F_{l i k k}$ and $\Delta F_{n i-k}$ are the cutting loads of elemental blade in the absolute coordinate system. The cutting load of 


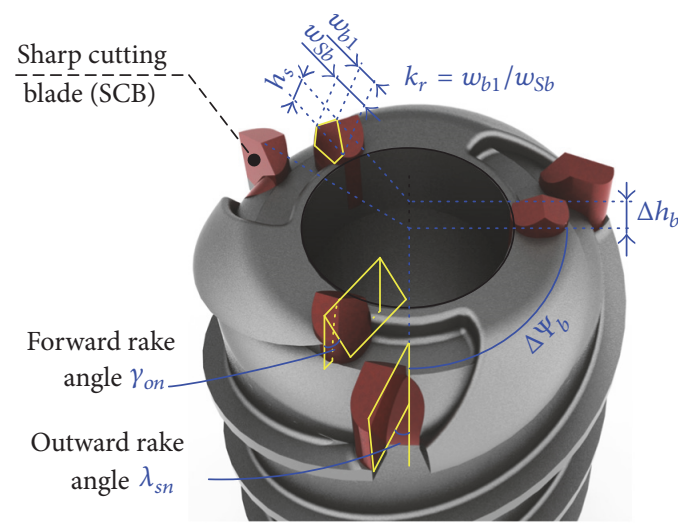

(a) Three-dimensional configuration illustration

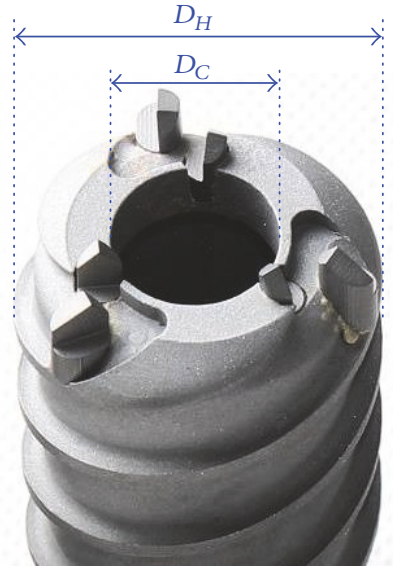

(b) The actual LRCB

FIGURE 1: Three-dimensional configuration illustration of the LRCB and the actual LRCB.

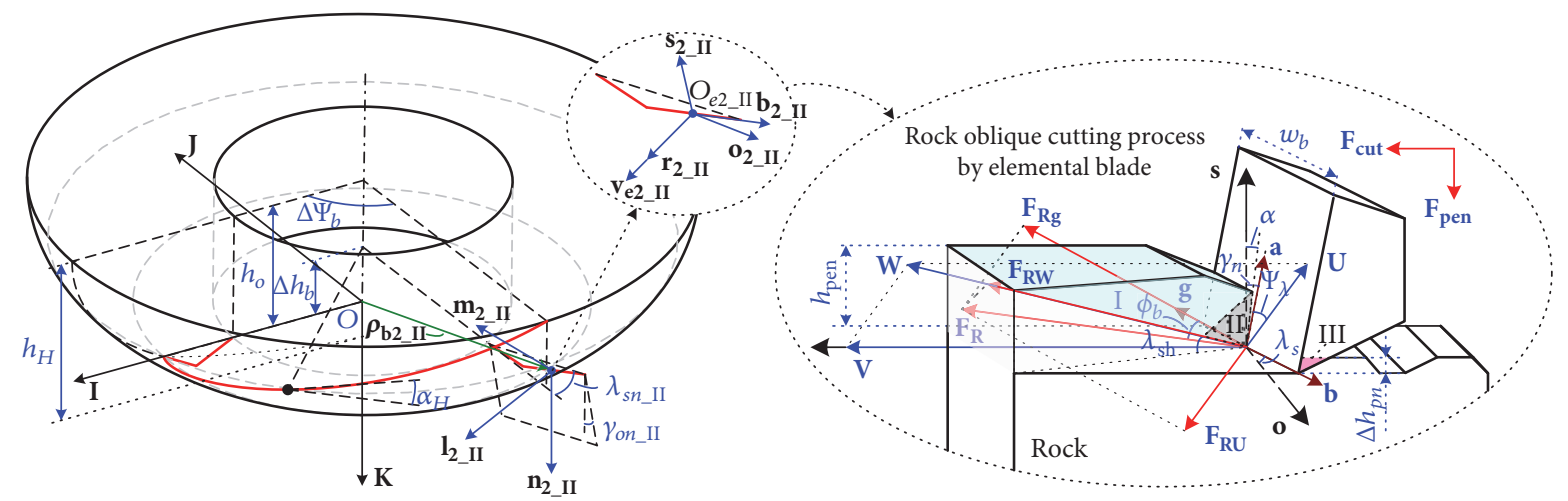

FIGURE 2: Curves for the LRCB's dual-row sharp cutting blade and matrix ellipsoid spiral chip removal.

TABLE 1: LRCB configuration parameters.

\begin{tabular}{|c|c|c|c|}
\hline \multicolumn{2}{|c|}{ Parameter } & Symbol & Value \\
\hline \multirow{4}{*}{ Bit matrix parameters } & Borehole diameter & $D_{H}$ & $32 \mathrm{~mm}$ \\
\hline & Coring diameter & $D_{C}$ & $14.5 \mathrm{~mm}$ \\
\hline & Short axial length of spiral ellipsoid & $h_{H}$ & $15.8 \mathrm{~mm}$ \\
\hline & Number of bit spirals & $N_{H}$ & 3 \\
\hline \multirow{2}{*}{ Cutting blade position parameters } & Cutting blade height difference & $\Delta h_{b}$ & $1 \mathrm{~mm}$ \\
\hline & Cutting blade angle difference & $\Delta \psi_{b}$ & $93.08^{\circ}$ \\
\hline \multirow{7}{*}{ Cutting blade configuration parameters } & \multirow{2}{*}{ Forward rake angle } & \multirow{2}{*}{$\gamma_{o n}$} & Row I: $0^{\circ}$ \\
\hline & & & Row II: $0^{\circ}$ \\
\hline & \multirow[t]{2}{*}{ Outward rake angle } & \multirow[t]{2}{*}{$\lambda_{s n}$} & Row I: $25^{\circ}$ \\
\hline & & & Row II: $25^{\circ}$ \\
\hline & Sharp-point position coefficient & $k_{r}$ & $\begin{array}{l}\text { Row l: } 0.5 \\
\text { Row II: } 0.3\end{array}$ \\
\hline & Sharp-point height & $h_{s}$ & $\begin{array}{l}\text { Row I: } 2 \mathrm{~mm} \\
\text { Row II: } 2 \mathrm{~mm}\end{array}$ \\
\hline & Sharp blade width & $w_{S b}$ & $\begin{array}{c}\text { Row I: } 4 \mathrm{~mm} \\
\text { Row II: } 5.33 \mathrm{~mm}\end{array}$ \\
\hline
\end{tabular}


the elemental blade in the local coordinate system $\{\mathbf{o}, \mathbf{s}, \mathbf{r}\}$ is calculated first. Next, a coordinate transformation is performed to obtain the result. An analysis of the stress on the elemental blade in the local coordinate system $\{\mathbf{o}, \mathbf{s}, \mathbf{r}\}$ is shown in Figure 2. The cutting and fracture region of the rock for a shallow cutting depth (approximately $100 \mu \mathrm{m}$ ) is divided into the following parts [23]: (i) a shear fracture region (I), in which the rock is mainly under the cutting force and develops a shear-tensile fracture; (ii) a dense core crushing area (II), which is an area of compressed dense powder produced by the cutting force, $F_{\text {Cut }}$, and the cutting pressure, $F_{\text {Pen }}$; and (iii) an overcut area (III), that is, a region in which the fracture near a predefined cutting depth is produced by fluctuations in the cut, contact friction, and the system's rigidity, which primarily affects the cutting pressure. The cutting force $F_{\text {Cut }}$ and the cutting pressure $F_{\mathrm{Pen}}$ of the elemental blade are as follows:

$$
\begin{aligned}
F_{\mathrm{Cut}} & =\left[F_{R}\left(\cos \phi_{b} \cdot \mathbf{g}-\sin \phi_{b} \cdot \frac{\mathbf{U}}{U}\right)\right. \\
+ & \left.F_{N}\left(\cos \phi_{B} \cdot \mathbf{g}_{\boldsymbol{\beta}}-\sin \phi_{B} \cdot \mathbf{a}_{\boldsymbol{\beta}}\right)\right] \cdot \mathbf{r}, \\
F_{\mathrm{Pen}} & =\left[F_{R}\left(\cos \phi_{b} \cdot \mathbf{g}-\sin \phi_{b} \cdot \frac{\mathbf{U}}{U}\right)\right. \\
+ & \left.F_{N}\left(\cos \phi_{B} \cdot \mathbf{g}_{\boldsymbol{\beta}}-\sin \phi_{B} \cdot \mathbf{a}_{\boldsymbol{\beta}}\right)\right] \cdot \mathbf{s},
\end{aligned}
$$

where $F_{R}$ is resultant force on the rock fragment due to the front blade surface; $F_{N}$ is resultant force on the overcut area due to the rear blade surface; $\phi_{b}$ is friction angle between the cutting blade and the dense core; $\phi_{B}$ is friction angle between the cutting blade and the parent rock; $\mathbf{g}$ is normal vector of the front blade surface; $\mathbf{U}$ is chip removal velocity vector; $\mathbf{g}_{\boldsymbol{\beta}}$ is unit vector normal to the rear blade surface; and $\boldsymbol{\alpha}_{\beta}$ is unit vector normal to the rear surface of the inward cutting blade.

In (2), the chip removal velocity vector, $\mathbf{U}$, satisfies

$$
\mathbf{U}=r V\left(\cos \psi_{\lambda} \cdot \mathbf{a}+\sin \psi_{\lambda} \cdot \mathbf{b}\right),
$$

where $r$ is removal-cutting ratio (the ratio between the removing vector and the cutting vector); $\psi_{\lambda}$ is chip removal angle (the angle between the direction of chip removal at the front blade surface and the direction normal to the cutting blade); $\mathbf{a}$ is unit vector normal to the front surface of the cutting blade; and $\mathbf{b}$ is unit vector parallel to the cutting blade.

Based on minimum energy dissipation theory, when the system's other control parameters are constants, there must be a group of state parameters $\left\{r, \psi_{\lambda}\right\}$ that minimize the power consumed by the front surface of the cutting blade. The obtained state parameters $\left\{r, \psi_{\lambda}\right\}$ are substituted into (2) to obtain the cutting load on the elemental blade. For a detailed derivation of the LRCB's drilling load, please refer to [20].

Because the process of sampling the lunar surface is based on controlling the drilling velocity, the LRCB's drilling parameters are generalized as the rotational velocity, $n_{D}$, and the penetration rate, $v_{\mathrm{Pen}}$. The penetrations per revolution (PPR) are defined as the ratio of these two control parameters, and its actual physical significance is the progress of bit as it

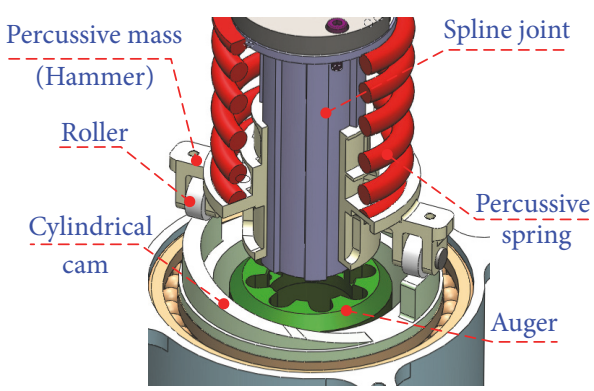

FIGURE 3: Three-dimensional configuration of the percussive mechanism.

penetrates vertically during each rotation. When the drill bit progresses at a constant PPR, each cutting blade performs a downward spiral. After the cutting blade cuts around the bit's center of rotation for a cycle, the corresponding penetration displacement is the product of the number of cutting blades and a single-blade's cutting depth, as shown in

$$
k_{\mathrm{PPR}}=\frac{v_{\mathrm{Pen}}}{n_{D}}=N_{b} \cdot h_{\mathrm{Pen}} \text {, }
$$

where $h_{\text {Pen }}$ is the real-time cutting depth of a single cutting blade during the drilling process and $N_{b}$ is the number of cutting blades deployed around the bit.

\section{Mechanical Model for Rotary-Percussive Drilling}

3.1. Analysis of the Rotary-Percussive Drilling Process. In the process of lunar surface sampling, applying a certain amount of impact load to the drill effectively improves its efficiency at fracturing lunar rock simulant. According to the design of the deep drilling/sampling mechanism for use on the lunar surface, the principle underlying the operation of the percussive mechanism is as follows: when the motor rotates the cylindrical cam, it also drives the cyclic motion of a set of spring-mass elements to apply an impact load to the drill, as shown in Figure 3 [24, 25].

In rotary-percussive drilling process, the cutting blades interact directly with the rock. When rotary-percussive drilling of lunar rock with a coring bit is expanded along the bit's circumferential direction, it is equivalent to rock cutting and percussive fracturing using an elemental blade along a straight line, as shown in Figure 4.

Impact-cutting and fracture of lunar rock simulant using a single blade is divided into the following stages (as shown in Figure 4): (i) the impact-cutting coupling stage: the impact load is suddenly applied to the cutting blade during forward cutting by a hammer; at the same time, the cutting blade quickly changes its original track, penetrates the rock along a direction that combines the percussion velocity and the cutting velocity, and creates a tiny impact fracture pit; (ii) the force-control cutting stage: because the effective impact time is extremely short (far less than the time required for the cam to return), the cutting blade progresses in response to a percussive spring pretightening force to cut and fracture the 


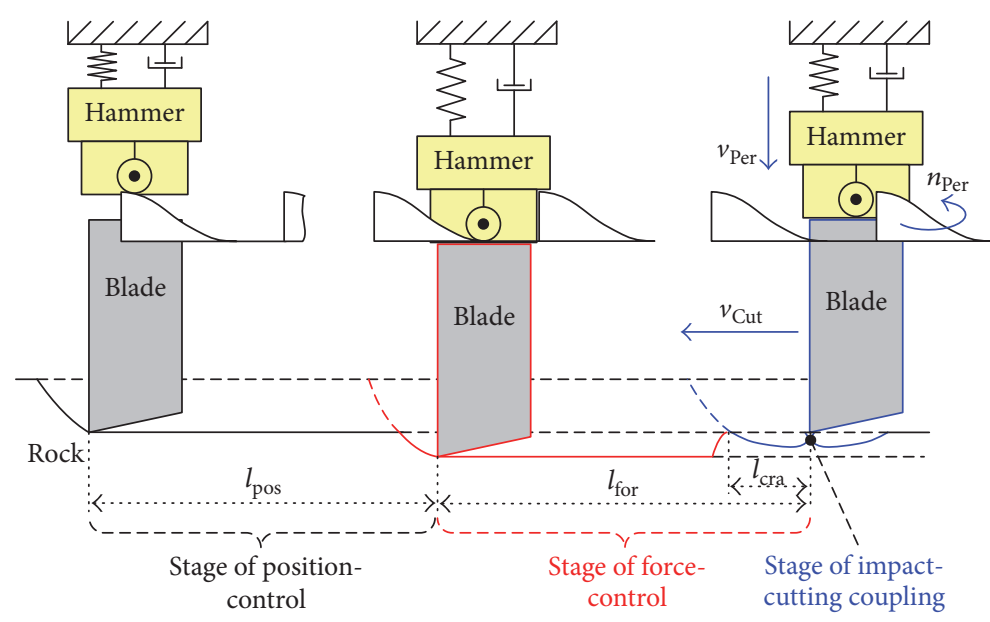

FIGURE 4: Fracture process for lunar rock simulant with impact-cutting coupling.

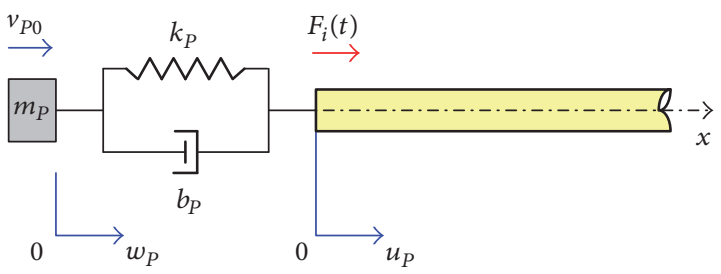

FIGURE 5: Simplified mechanical model of the collision between the hammer and the drill.

rock after the impact load disappears; at the same time, the cutting depth of the rock is determined by the pretightening force of the percussive spring; and (iii) the position-control cutting stage: when the hammer and the roller start the next cycle of motion, the percussive spring pretightening force on the cutting blade disappears; at the same time, the cutting blade enters the position-control cutting stage; that is, it completely follows the predefined cutting depth to fracture the lunar rock simulant. Now, the impact load cycle is complete, and the cutting blade waits for the next impact.

\subsection{Mechanical Model of the Collision between the Hammer} and the Drilling Tool. Assume the hammer's collision with the drill is an interaction between a single mass block and a semi-infinite polished rod via a spring damping element without the additional effect of reflected waves on the percussive stress, as shown in Figure 5 [26].

According to Newton's second law and the equation for the transmission of a one-dimensional stress wave transmission, the collision between the hammer and the drill should satisfy the following equations and boundary conditions:

$$
\begin{aligned}
& m_{P} \ddot{w}_{P}=-k_{P}\left(w_{P}-u_{P}\right)-b_{P}\left(\dot{w}_{P}-\dot{u}_{P}\right), \\
& b_{P} \dot{w}_{P}+k_{P} w_{P}-\left(b_{P}+\frac{E A}{c}\right) \dot{u}_{P}-k_{P} u_{P}=0,
\end{aligned}
$$

$$
\begin{aligned}
& w_{P}(0)=0, \\
& \dot{w}_{P}(0)=v_{P 0}, \\
& u_{P}(0)=0
\end{aligned}
$$

where $m_{P}$ is hammer mass; $E$ is elastic modulus of the drill material; $A$ is contact area between the hammer and the drill during the collision; $k_{P}$ is contact rigidity of the hammer and the drill during the collision; and $b_{P}$ is equivalent damping coefficient of the hammer and the drill during the collision.

The Laplace transform of (5) is taken, variables are substituted, and the Laplace transform is inverted to obtain

$$
\begin{aligned}
& w_{P}(t)=\frac{v_{P 0}}{2 \eta_{P}}\left\{1-e^{-\alpha_{P} t} \cos \omega_{P} t+\beta_{P 1} e^{-\alpha_{P} t} \sin \omega_{P} t\right\}, \\
& u_{P}(t)=\frac{v_{P 0}}{2 \eta_{P}}\left\{1-e^{-\alpha_{P} t} \cos \omega_{P} t-\beta_{P} e^{-\alpha_{P} t} \sin \omega_{P} t\right\},
\end{aligned}
$$

where

$$
\begin{aligned}
\omega_{P}^{2} & =\frac{16 \eta_{P}^{2} \omega_{P 0}^{2}-\left(\omega_{P 0}^{2}-4 \xi_{P} \eta_{P}\right)^{2}}{16\left(\xi_{P}+\eta_{P}\right)^{2}}, \\
\alpha_{P} & =\frac{\omega_{P 0}^{2}+4 \xi_{P} \eta_{P}}{4\left(\xi_{P}+\eta_{P}\right)}, \\
\beta_{P 1} & =\frac{8 \eta_{P}^{2}-\omega_{P 0}^{2}+4 \xi_{P} \eta_{P}}{4\left(\xi_{P}+\eta_{P}\right) \omega_{P}}, \\
\beta_{P} & =\frac{\omega_{P 0}^{2}-4 \xi_{P} \eta_{P}}{4\left(\xi_{P}+\eta_{P}\right) \omega_{P}}
\end{aligned}
$$




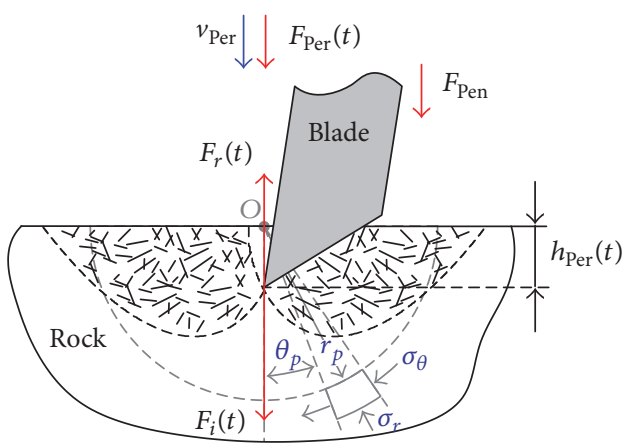

FIGURE 6: Stress analysis of the percussive fracture of lunar rock simulant via the cutting blade.

and $\xi_{P}, \eta_{P}$, and $\omega_{P 0}$ satisfy

$$
\begin{aligned}
\frac{b_{P}}{m_{P}} & =2 \xi_{P}, \\
\frac{E A}{c m_{P}} & =2 \eta_{P}, \\
\frac{k_{P}}{m_{P}} & =\omega_{P 0}^{2} .
\end{aligned}
$$

The impact force on the contact surface is

$$
F_{i}(t)=m v_{0} \sqrt{1+\beta^{2}} \sqrt{\alpha^{2}+\omega^{2}} e^{-\alpha t} \sin (\omega t+\varphi) .
$$

3.3. Model of the Impact-Cutting Coupling Stage. In a complete impact load cycle, because the effective impact time is extremely short (several milliseconds), the horizontal motion of the cutting blade during this cycle is ignored; that is, the fracture of the lunar rock simulant due to the impact-cutting coupling is discretized as a percussive fracture process and a cutting fracture process.

3.3.1. Mechanical Model of the Percussive Penetration of the Elemental Blade into the Lunar Rock Simulant. As with a single impact, the interaction between the cutting blade and the rock is extremely short. The load, $F_{\mathrm{Per}}$, on the rock due to the cutting blade and the penetration depth, $h_{\mathrm{Per}}$, satisfy the following relation (the variation of the rock's contact rigidity during the loading/offloading process is ignored):

$$
F_{\text {Per }}=K h_{\text {Per }}
$$

where $K$ represents the contact rigidity of the rock.

An analysis of the stress at the instant of percussive fracture of the lunar rock simulant via the cutting blade is shown in Figure 6. Based on the fluctuation dynamics, the percussion is transmitted as a fluctuation via the cutting blade to the rock. On the contact surface between the cutting blade and the rock, the wave is transmitted and reflected. Based on force equilibrium and fluctuation dynamics, the relationship between the incident/reflected stress and the velocity is

$$
\begin{aligned}
\frac{d F_{\mathrm{Per}}}{d t} & =K \frac{d h_{\mathrm{Per}}}{d t}=K v_{\mathrm{Per}}, \\
F_{\mathrm{Per}}(t) & =2 F_{i}(t)-Z \cdot v_{\mathrm{Per}}(t)+F_{\mathrm{Pen}},
\end{aligned}
$$

where $v_{\text {Per }}$ is velocity of the cutting blade's percussive penetration into the rock; $F_{i}(t)$ is cutting blade's incident impact force on the rock; $F_{\text {Pen }}$ is cutting blade's pressure on the rock; $Z$ is wave damping of the drill.

After substituting variables and rearranging (11), a differential equation or the percussive fracture of lunar rock simulant by a cutting blade is as follows:

$$
\frac{d F_{\mathrm{Per}}}{d t}+\frac{K}{Z} \cdot F_{\mathrm{Per}}=\frac{2 K}{Z} F_{i}+\frac{K}{Z} F_{\mathrm{Pen}} .
$$

When the initial condition $\left.F_{\text {Per }}\right|_{t=0}=0$ is substituted into the incident percussion equation (9), the impact force that the cutting blade exerts to fracture the lunar rock simulant is

$$
\begin{aligned}
F_{\text {Per }} & =e^{-K^{*} \cdot t} \cdot K^{*} \cdot \frac{2 m v_{0} \sqrt{1+\beta^{2}} \sqrt{\alpha^{2}+\omega^{2}}}{\left(K^{*}-\alpha\right)^{2}+\omega^{2}} \\
\cdot & \left\{e^{\left(K^{*}-\alpha\right) \cdot t}\right. \\
\cdot & {\left[\left(K^{*}-\alpha\right) \cdot \sin (\omega t+\varphi)-\omega \cdot \cos (\omega t+\varphi)\right] } \\
- & {\left.\left[\left(K^{*}-\alpha\right) \cdot \sin \varphi-\omega \cdot \cos \varphi\right]\right\}+F_{\mathrm{Pen}}(1} \\
- & \left.e^{-K^{*} \cdot t}\right),
\end{aligned}
$$

where $K^{*}$, the impact coefficient of the cutting blade on the rock, is equal to $K / Z$.

Because the percussive fracture region of the rock is much smaller than the width of the cutting blade, the impact force of the cutting blade on the rock calculated in the previous section is treated as a linear load. For a linear load $F_{\mathrm{Per}} / w_{b}$, the internal stress state of the rock (a semi-infinite plane, as shown in Figure 6) is

$$
\begin{aligned}
\sigma_{r} & =\frac{2 F_{\mathrm{Per}} \cos \theta_{p}}{\pi r_{p} w_{b}}, \\
\sigma_{\theta} & =0, \\
\tau_{r \theta} & =0,
\end{aligned}
$$

where $r_{p}$ is polar radius of pole $O$ in a polar coordinate system; $\theta_{p}$ is polar angle of pole $O$ in a polar coordinate system; $\sigma_{r}$ is normal stress on a microelement of the rock along the polar radius; $\sigma_{\theta}$ is normal stress on a microelement of the rock along the polar angle; and $\tau_{r \theta}$ is shear stress on a microelement of the rock along the polar radius/angle.

As shown in Figure 6, the shear stress $\tau_{r \theta}=0$; therefore, $\sigma_{r}$ and $\sigma_{\theta}$ are main stresses on the microelement of the lunar rock simulant. Under a linear load, shear cracks in rock 
normally spread along tracks that maintain constant angles with respect to the maximum principle stress. For a linear load, these tracks constitute two logarithmic spirals, as shown in

$$
r_{p}=r_{p 0} e^{ \pm \theta_{p} \cot \lambda_{f}}
$$

where $r_{p 0}$ is the distance between the intersection point of the two logarithmic spirals and pole $O$ and $\lambda_{f}$ is the angle between the tangent at any point along the shear crack's track and the maximum principle stress at that point.

Next, based on equation of state for the stress on any microelement in an object under external load and (14) and (15), the shear stress, $\tau_{p}$, and the normal stress, $\sigma_{p}$, at any point on the logarithmic spiral are

$$
\begin{aligned}
\tau_{p} & =\frac{F_{\mathrm{Per}} \sin 2 \lambda_{f}}{\pi r_{p 0} w_{b}} e^{ \pm \theta_{p} \cot \lambda_{f}} \cos \left( \pm \theta_{p}\right), \\
\sigma_{p} & =\frac{F_{\mathrm{Per}}\left(1-\cos 2 \lambda_{f}\right)}{\pi r_{p 0} w_{b}} e^{ \pm \theta_{p} \cot \lambda_{f}} \cos \left( \pm \theta_{p}\right) .
\end{aligned}
$$

Additionally, rock fracture satisfies the Mohr-Coulomb yield theorem; that is, $\tau_{p}=\sigma_{p} \cdot \tan \varphi+C$. Equation (16) is substituted, and (17) is obtained after rearrangement.

$$
r_{p 0}=\frac{2 F_{\mathrm{Per}}\left(\sin \lambda_{f}\right)^{2}\left(\cot \lambda_{f}-\tan \varphi\right) \cos \left( \pm \theta_{p}\right)}{\pi w_{b} C e^{ \pm \theta_{p} \cot \lambda_{f}}} .
$$

Equation (17) suggests that when the rock surface is under a certain load, both sides of the load develop two shear cracks, as shown in Figure 6. These cracks satisfy relationship given by (15). The distance between the intersection of the two cracks and pole $O$ is $r_{p 0}$. This area is defined as the compressive dense area formed after the impact load is applied to rock. After $r_{p 0}$ is obtained, a complete profile of the impact fracture pit on the lunar rock simulant is obtained via (15).

\subsubsection{Analysis of the Cut Fracture Characteristics of Lunar} Rock Simulant during Impact. After an impact, two impact fracture pits are formed before and after the load is applied to the lunar rock simulant. While the cutting blade continues cutting forward, the lunar rock simulant continues to fracture along the shear fracture previously formed by the impact load. To simplify the stress analysis, the shear fracture surface of the rock during cutting is treated as a plane whose starting and end points are where the profile of the impact fracture pit (a logarithmic spiral) intersects the cut and uncut surfaces of the lunar rock simulant. When the impact and cutting are coupled, three regions are formed in front of the cutting blade (as shown in Figure 7); that is, OAGF is the compact fracture region formed by the impact; $\mathrm{ABCD}$ is the percussive fracture fragment formed by the impact; and BEC is the shear fracture

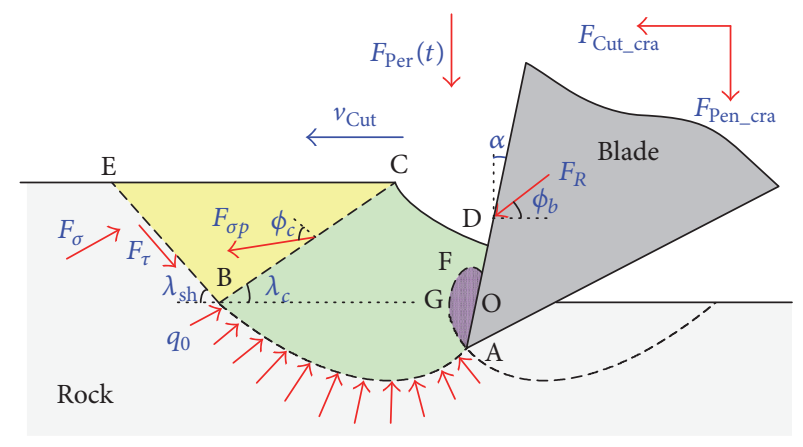

FIgURE 7: Stress analysis for lunar rock simulant fracture via an elemental blade by means of coupled impact and cutting.

region formed by cutting. The equilibrium equations are as follows:

$$
\begin{aligned}
& F_{R} \cos \left(\phi_{b}-\alpha_{x}\right)=F_{\sigma p} \cos \left(\lambda_{c}+\phi_{c}-\frac{\pi}{2}\right)+F_{n x} \\
& F_{R} \sin \left(\phi_{b}-\alpha_{x}\right)=F_{\sigma p} \sin \left(\lambda_{c}+\phi_{c}-\frac{\pi}{2}\right)+F_{n y}
\end{aligned}
$$

where $F_{R}$ is resultant force on the cutting blade; $F_{n x}$ is horizontal component of the resultant reaction force exerted by the parent rock on a rock fragment in the fracture region; and $F_{n y}$ is vertical component of the resultant reaction force exerted by the parent rock on a rock fragment in the fracture region.

In (19), $F_{\sigma p}$ satisfies following relationship:

$$
F_{\sigma p}=\frac{1}{n+1} \cdot \frac{h_{P n a} w_{b}}{\sin \lambda_{\mathrm{sh}}} \cdot \frac{C \cos \varphi}{\sin \left(\varphi+\phi_{c}+\lambda_{\mathrm{sh}}+\lambda_{c}\right)},
$$

where $n$ is stress distribution coefficient; $h_{P n a}$ is actual cut depth; $w_{b}$ is cutting blade width; $\lambda_{\mathrm{sh}}$ is shear fracture angle; $C$ s cohesion of the rock; $\varphi$ is inner friction angle of the rock; $\lambda_{c}$ is angle between the percussive fracture fragment and the cutting direction; and $\phi_{c}$ is friction angle between the percussive fracture fragment and the parent rock.

For the other parameters and variables in Figure 7 and (19), please refer to the stress analysis for the cutting and fracturing of lunar rock simulant using an elemental blade [17]. Before the resultant force on the cutting blade, $F_{R}$, is calculated, the resultant force exerted by the parent rock on a rock fragment in fracture region, $F_{n}$, should be calculated. Assume uniformly distributed force, $q$, in logarithmic spiral $\mathrm{AB}$ satisfies the following condition:

$$
q=q_{0} \cdot \sin \theta
$$

where $q_{0}$ is the stress constant.

The polar function in (15) is converted to rectangular coordinates as follows:

$$
\begin{aligned}
& x(\theta)=r \cdot \sin \theta=r_{0} e^{\theta \cot \lambda_{f}} \cdot \sin \theta, \\
& y(\theta)=r \cdot \cos \theta=-r_{0} e^{\theta \cot \lambda_{f}} \cdot \cos \theta .
\end{aligned}
$$


The arc length, $l_{m i}$, between any two polar angles $\theta_{i}$ and $\theta_{i+1}$ in the logarithmic spiral in the impact fracture pit is

$$
\begin{aligned}
l_{m i} & =\int_{\theta_{i}}^{\theta_{i+1}} \sqrt{\left(\frac{d x}{d \theta}\right)^{2}-\left(\frac{d y}{d \theta}\right)^{2}} d \theta \\
& =\left.\frac{r_{0} \sqrt{\left(\cot \lambda_{f}\right)^{2}+1}}{\cot \lambda_{f}} e^{\theta \cot \lambda_{f}}\right|_{\theta_{i}} ^{\theta_{i+1}} .
\end{aligned}
$$

The resultant force along any arc is

$$
\begin{aligned}
F_{n i} & =q_{0} \cdot \sin \theta_{m i} \cdot l_{s i} \\
& =\left.\frac{q_{0} r_{0} \sqrt{\left(\cot \lambda_{f}\right)^{2}+1}}{\cot \lambda_{f}} \sin \theta_{m i} \cdot e^{\theta \cot \lambda_{f}}\right|_{\theta_{i}} ^{\theta_{i+1}},
\end{aligned}
$$

where $\theta_{m i}$ is the polar angle corresponding to the midpoint of the arc between adjacent polar angles $\theta_{i}$ and $\theta_{i+1} ; \theta_{m i} \approx$ $\left(\theta_{i}+\theta_{i+1}\right) / 2$.

The horizontal and vertical components of the resultant reaction force exerted by the parent rock on a rock fragment in fracture region are

$$
\begin{aligned}
& F_{n x}=\sum_{i=1}^{n} F_{n i} \cdot \cos \varphi_{n i}, \\
& F_{n y}=\sum_{i=1}^{n} F_{n i} \cdot \sin \varphi_{n i},
\end{aligned}
$$

where $\varphi_{n i}$ is the angle between the normal vector/reaction force at the midpoint of arc microelement $l_{s i}$ and the horizontal direction;

$$
\tan \varphi_{n i}=\frac{\cot \lambda_{f} \sin \theta_{m i}+\cos \theta_{m i}}{\cot \lambda_{f} \cos \theta_{m i}-\sin \theta_{m i}}
$$

Equations (23) and (25) are substituted into (24) to obtain the horizontal and vertical components of the resultant reaction force exerted by the parent rock on a rock fragment in the fracture region,

$$
\begin{gathered}
F_{n x}=\frac{q_{0} r_{0} \sqrt{\left(\cot \lambda_{f}\right)^{2}+1}}{\cot \lambda_{f}} \\
\cdot \sum_{i=1}^{n}\left(\sin \theta_{m i} \cdot e^{\left.\theta \cot \lambda_{f}\right|_{\theta_{i}} ^{\theta_{i+1}}}\right) \cdot \cos \varphi_{n i}, \\
F_{n y}=\frac{q_{0} r_{0} \sqrt{\left(\cot \lambda_{f}\right)^{2}+1}}{\cot \lambda_{f}} \\
\cdot \sum_{i=1}^{n}\left(\left.\sin \theta_{m i} \cdot e^{\theta \cot \lambda_{f}}\right|_{\theta_{i}} ^{\theta_{i+1}}\right) \cdot \sin \varphi_{n i} .
\end{gathered}
$$

Equation (26) is substituted into (18) to obtain

$$
\begin{aligned}
& F_{R} \\
& =\frac{\cos \left(\lambda_{c}+\phi_{c}-\pi / 2\right) \cdot K_{F n y}-\sin \left(\lambda_{c}+\phi_{c}-\pi / 2\right) \cdot K_{F n x}}{\cos \left(\phi_{b}-\alpha_{x}\right) \cdot K_{F n y}-\sin \left(\phi_{b}-\alpha_{x}\right) \cdot K_{F n x}} \\
& \quad \cdot F_{\sigma p},
\end{aligned}
$$

where

$$
\begin{aligned}
K_{F n x} & =\sum_{i=1}^{n}\left(\left.\sin \theta_{m i} \cdot e^{\theta \cot \lambda_{f}}\right|_{\theta_{i}} ^{\theta_{i+1}}\right) \cdot \cos \varphi_{n i}, \\
K_{F n y} & =\sum_{i=1}^{n}\left(\left.\sin \theta_{m i} \cdot e^{\theta \cot \lambda_{f}}\right|_{\theta_{i}} ^{\theta_{i+1}}\right) \cdot \sin \varphi_{n i} .
\end{aligned}
$$

When impact and cutting are coupled, the cutting force and cutting pressure required by a single cutting blade to fracture lunar rock simulant are as follows:

$$
\begin{aligned}
& F_{\text {Cut_cra }}=F_{R} \cdot \cos \left(\phi_{b}-\alpha\right), \\
& F_{\text {Pen_cra }}=F_{R} \cdot \sin \left(\phi_{b}-\alpha\right) .
\end{aligned}
$$

3.4. Fracture Load Analysis for Lunar Rock Simulant in the Force- and Position-Control Cutting Stages. The depth of a cut in lunar rock simulant during the force-control cutting stage is determined by the percussive spring pretightening force. If the percussive spring pretightening force exceeds the cutting pressure required to cut and fracture rock, the actual cut depth exceeds the initial predefined cut depth. Otherwise, the cutting blade fractures the lunar rock simulant according to predefined cut depth. Moreover, the cutting load in the force-control cutting stage is affected by both the percussive spring pretightening force and the impact load. In the impactcutting coupling stage, the lunar rock simulant develops an impact fracture pit during the impact. While the cutting blade continues cutting forward, the rock fractures along the trail of the impact fracture pit. Therefore, part of the load in the forcecontrol cutting stage is due to the impact pit in the fractured lunar rock. Additionally, when the cutting velocity is fixed, horizontal cut displacement in the force-control cutting stage is primarily affected by the percussion frequency. A higher percussion frequency leads to a smaller cut displacement; that is, a higher percussion frequency leads to a smaller displacement in the force-control cutting stage. It takes more time for the cutting blade to cross an impact fracture pit, and the load required to fracture lunar rock simulant increases when there is an impact pit. The average load required to fracture lunar rock simulant in the force-control cutting stage is

$$
\begin{aligned}
& F_{F C u t \_a v e}=F_{\text {Cut_cra }} \cdot K_{\text {cra }}+F_{\text {Cut_pre }} \cdot K_{\text {pre }}, \\
& F_{\text {Fen_ave }}=F_{\text {Pen_cra }} \cdot K_{\text {cra }}+F_{\text {Pen_pre }} \cdot K_{\text {pre }},
\end{aligned}
$$

where $F_{\text {Cut_cra }}$ is cutting force required to complete the first cutting cycle after the impact fracture pit is formed; $F_{\text {Pen_cra }}$ is cutting pressure required to complete first cutting cycle after the impact fracture pit is formed; $K_{\text {cra }}$ is weight coefficient of 


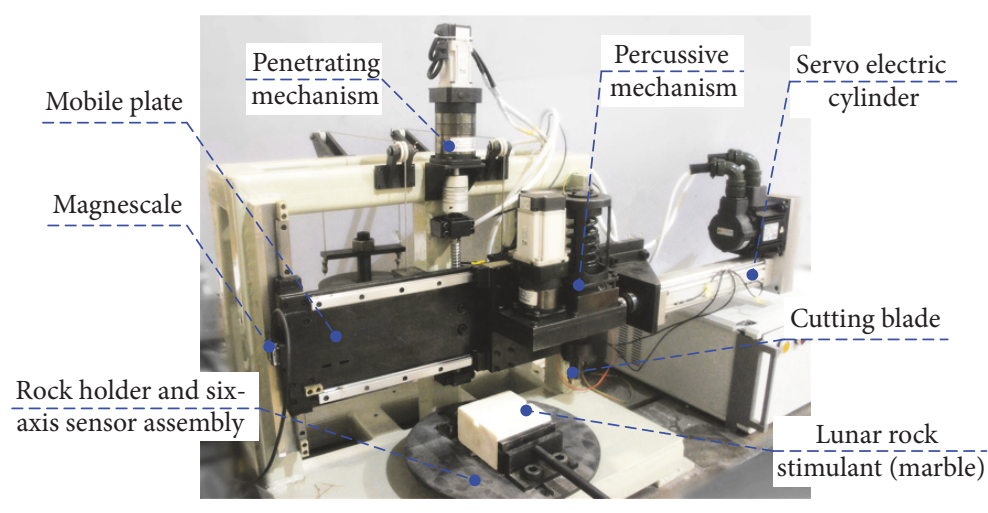

(a)



(b)

FIGURE 8: Single-blade linear cutting load test platform (a) and comprehensive drill characteristics test platform (b).

the required cutting load to complete the first cutting cycle after the impact fracture pit is formed; $F_{\text {Cut_pre }}$ is cutting force required to cut the rock with a percussive spring pretightening force; $F_{\text {Pen pre }}$ is cutting pressure required to cut the rock with a percussive spring pretightening force; $K_{\text {pre }}$ is weight coefficient of the cutting load for the pretightening force.

In (30), the weight coefficient satisfies the following condition:

$$
\begin{aligned}
K_{\text {cra }} & =\frac{t_{\text {cra }}}{t_{\text {for }}}=\frac{2 \pi \cdot l_{\text {cra }} \cdot f_{p}}{v_{\text {cut }} \cdot \beta_{c 1} \cdot n_{\mathrm{cb}}}, \\
K_{\text {pre }} & =1-K_{\text {cra }},
\end{aligned}
$$

where $t_{\text {cra }}$ is time required for the cutting blade to cross the impact fracture pit; $t_{\text {for }}$ is time required for the cutting blade to complete the force-control cutting stage; $l_{\text {cra }}$ is horizontal displacement of the impact fracture pit; $f_{p}$ is percussion frequency; $v_{\mathrm{Cut}}$ is horizontal velocity of the cutting blade; $\beta_{c 1}$ is idle movement angle of the cam in percussive mode; and $n_{\mathrm{cb}}$ is number of bulges in the cam in percussive mode.

The cutting load characteristics of lunar rock simulant under force-control cutting conditions are essentially the same as those with a predefined cut depth. Therefore, the calculation of the cutting load of lunar rock simulant under force-control cutting conditions given in (30) is based on (2).

When the percussive cam changes from being idle to traveling, the hammer moves upward along the convex profile and compresses the percussive spring to accumulate energy for next impact load. At the same time, the hammer is no longer pressed to the top of cutting blade's post, and the cutting blade is temporarily free. As the cut continues, the cutting blade is quickly lifted by the uncut surface of the lunar rock simulant and clings to the upper boundary of the tool post. At the same time, the lunar rock simulant is cut and fractured according to the predefined cut depth.

\section{Experimental Verification}

The experimental verification of the characteristics of the load for rotary-percussive drilling with an LRCB is divided into two stages. First, the impact-cutting load characteristics are tested using a single-blade linear cutting load test platform to verify the characteristics of the load on the cutting blade in different stages. Next, a rotary-percussive drilling test of the lunar rock simulant is performed via a comprehensive test platform for the characteristics of the drill to compare the variation trends of the drilling load before and after the impact load is applied and to analyze and verify the characteristics of the LRCB drilling load for different drilling parameters. Based on the specifications in the Change plan for experimental verification of the LRCB's ground functionality, marble of grade-VI drillability is selected to simulate lunar rock.

4.1. Test Environment Overview. The single-blade linear cutting load test platform is shown in Figure 8(a). The cutting blade installed in the mobile plate is driven by a servo actuator to make a horizontal cut. The front panel of the mobile plate is connected to the penetrating mechanism to make the cutting blade penetrate vertically. Additionally, the percussive mechanism (which is driven according to the theory shown in Figure 3 ) is attached to the top of the cutting blade's post to apply an impact to the cutting blade. A magnescale sensor is installed on the left side of the front panel to monitor the cutting blade's penetration displacement and fluctuations in the cut in real-time. A rock holder is installed on the platform rack by means of a six-axis force sensor to measure the cutting and impact loads on the rock in real-time during the cutting/percussion process [27].

The comprehensive drilling/sampling characteristics test platform is shown in Figure 8(b). The bit is installed in a rotary-percussive drill via a $1 \mathrm{~m}$ hollow auger. Guide rails are installed on both sides of the drill box and connected to the penetration mechanism via the drive chain. The drill and the penetration mechanism drive the LRCB during rotarypercussive drilling. Tension and torque sensors are installed in the drive chain and along the axis of the auger, respectively, to measure the drilling pressure and the torque on the coring bit in real-time. A magnescale sensor is installed between the drill box and the guide rails to measure the penetration displacement [28]. 


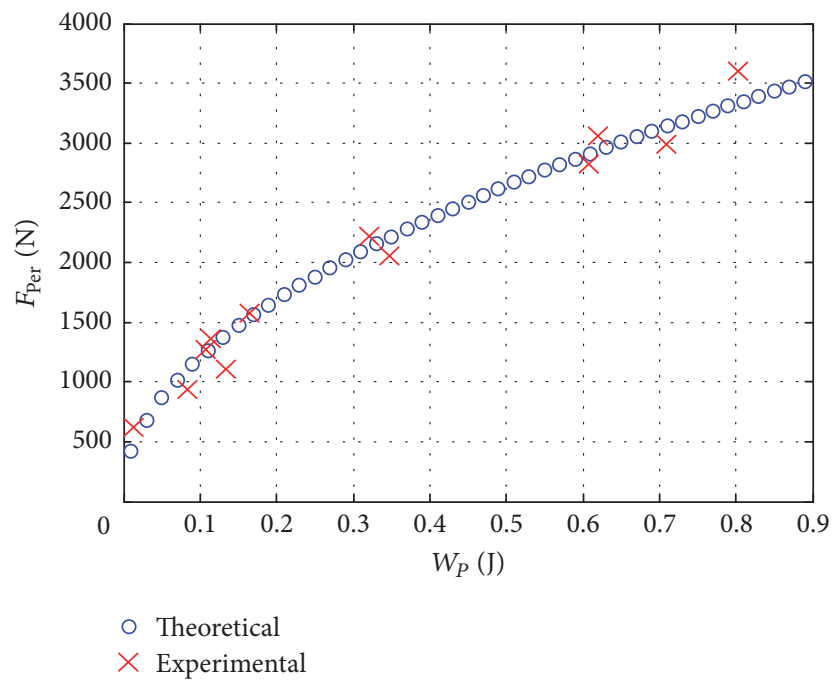

FIGURE 9: Maximum impact load on the lunar rock simulant with the percussion energy increase.

4.2. Experimental Verification of the Cutting Impact Load Characteristics for Lunar Rock Simulant. According to the theoretical model described in the previous sections, the impact load on the lunar rock simulant is related to the collision contact rigidities of the hammer and cutting blade's post and between the cutting blade and the lunar rock simulant. The lunar rock simulant's impact load transmission characteristics are tested to obtain these two contact rigidity coefficients. The pattern in the lunar rock simulant's variations when it is impacted with different percussion energies is tested to calibrate the two contact rigidities during collision in the model. The variation pattern of the maximum impact load as a function of the percussion energy exerted by the cutting blade on the lunar rock simulant is shown in Figure 9. In the test, the percussive spring pretightening force is adjusted to vary the percussion energy. As the percussion energy increases from $0.0138 \mathrm{~J}$ to $0.8027 \mathrm{~J}$, the maximum impact load on the lunar rock simulant increases from $623.2 \mathrm{~N}$ to $3,598 \mathrm{~N}$. Using the method of undetermined coefficients, the collision contact rigidities between the hammer and the cutting blade's post and between the cutting blade and the lunar rock simulant are obtained; they are listed in Table 2. The other parameters of the model are obtained from a test of the rock's mechanical characteristics and a discrete element simulation of the single-blade linear cutting process.

Because the effect of the cut configuration on the transmission loss of the impact load is insignificant, a $4 \mathrm{~mm}$ wide cutting blade with $\mathrm{a}-13^{\circ}$ front rake angle and a $0^{\circ}$ blade rake angle is used for the percussive cutting and fracture of lunar rock simulant via a single blade in the load characteristics test. When the cut depth is $0.033 \mathrm{~mm}$, the cutting velocity is $26.1 \mathrm{~mm} / \mathrm{s}$, the percussion energy is $0.28 \mathrm{~J}$, the percussion frequency is $4 \mathrm{~Hz}$, and the cutting pressure load as a function of time for the lunar rock simulant in a single impact cycle is as shown in Figure 10(a). The solid blue line represents the test load. After one cycle of impact loading, the cutting pressure on the lunar rock simulant peaks instantaneously,
TABLE 2: Characteristic parameters in the rotary-percussive drilling load prediction model for lunar rock simulant.

\begin{tabular}{lc}
\hline Rock material & Marble \\
Cohesion & $24.2 \mathrm{MPa}$ \\
Inner friction angle & $41.8^{\circ}$ \\
Indentation hardness & $1080 \mathrm{MPa}$ \\
Friction angle between rock fragments and parent & $32.2^{\circ}$ \\
rock & $60^{\circ}$ \\
Angle between dense core and cut fracture & $20 \mathrm{kN} / \mathrm{mm}$ \\
Contact rigidity between hammer and tool post & $21 \mathrm{kN} / \mathrm{mm}$ \\
\hline
\end{tabular}

falls rapidly, enters the force-control cutting stage (the light yellow area), and stabilizes at approximately $151 \mathrm{~N}$ (which is commensurate with the percussive spring pretightening force). When the percussive cam begins to push it, the cutting blade enters the position-control cutting stage (the light grey area). When the pretightening force on the tool post is instantaneously released, the cutting blade is lifted rapidly by the cutting area of the rock and progresses according to the predefined cut depth. The cutting pressure stabilizes at approximately $23.1 \mathrm{~N}$. Because there are assembly gaps and elastic deformation between the rack and the tool post, the rigidity of the system and the overcut depth, $\Delta h_{P n}$, vary during the cutting process. Figure 10(b) shows the variation trend of the impact load on the lunar rock simulant versus time. It shows that the theoretical variation curve for the impact load essentially matches the experimental one.

The average penetration distance is defined as the calibration value of the fluctuation in the cut depth, $\Delta h_{P n}$. The fluctuations in the cut depth as a function of the cut depth and the percussion frequency during the force- and positioncontrol cutting stages are obtained via fitting as follows:

$$
\begin{aligned}
& \Delta h_{P n_{-} \text {for }}=\left(39450 \cdot h_{\text {Pen }}^{2}+22290 \cdot h_{\text {Pen }}+6883\right) \\
& \quad \times 10^{-6}, \\
& \Delta h_{P n_{-} \text {pos }}=\left(-21.11+764.8 h_{\text {Pen }}+1.315 f_{P}\right. \\
& \quad-5924 h_{\text {Pen }}^{2}+1.119 h_{\text {Pen }} \cdot f_{P}+20210 h_{\mathrm{Pen}}^{3} \\
& \left.\quad-41.71 h_{\text {Pen }}^{2} \cdot f_{P}\right) \times 10^{-4} .
\end{aligned}
$$

For different cut depths and percussion frequencies, the average cutting impact load on the lunar rock simulant is shown in Figure 11. Figures 11(a) and 11(b) show curved surfaces representing the variation of the load on the lunar rock simulant during the force-control cutting stage. In this stage, the cutting load is inversely proportional to the percussion frequency. This is mainly because as the percussion frequency increases, the proportion of the fracture load to which the impact-cutting coupling condition applies increases, and a smaller shear fracture angle becomes sufficient to complete the fracture in the lunar rock simulant under the impactcutting coupling condition. Therefore, the average load gradually decreases. Moreover, with the increase in the cut depth, 




(a)

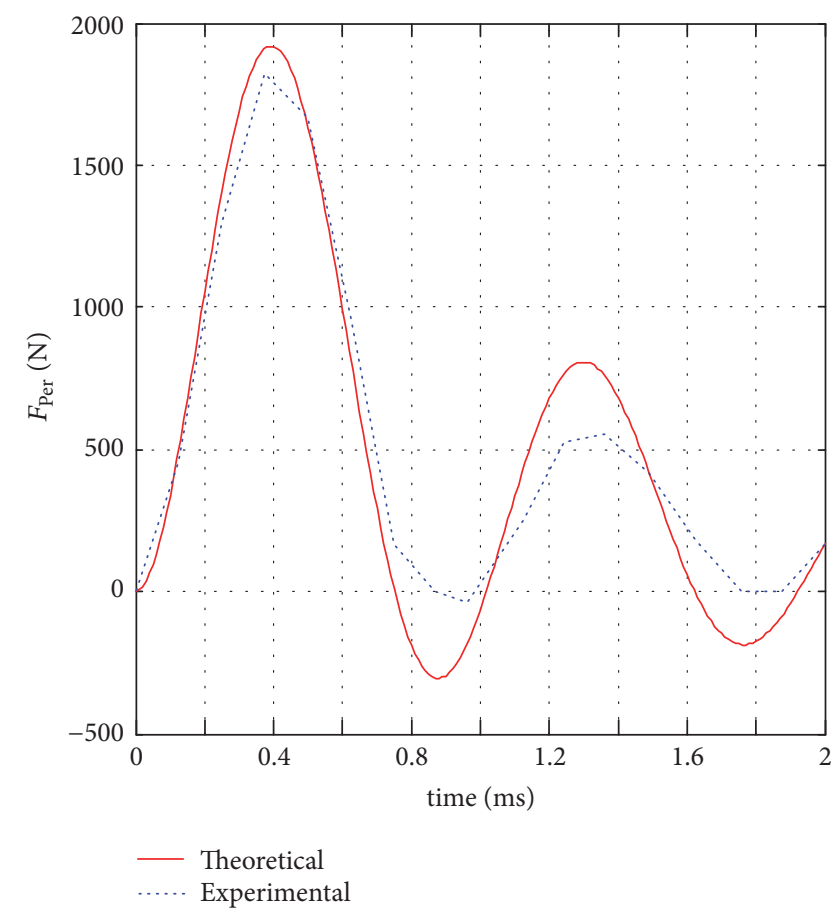

(b)

FIGURE 10: Variation trend of the resistant force on the lunar rock simulant in a single impact cycle.

the cutting load becomes clearly divided into two stages. When the cut depth is less than $0.1 \mathrm{~mm}$, no variation of fracture load on the lunar rock simulant is apparent. This is because when there is a percussive spring pretightening force, a cut with a depth of $0.1 \mathrm{~mm}$ is made on the lunar rock simulant; for comparison, when cut depth exceeds $0.1 \mathrm{~mm}$, the fracture load increases significantly with the cut depth, and the percussive spring pretightening force never plays a dominant role. Figures 11 (c) and 11(d) show curved surfaces that represent the variation in the load on the lunar rock simulant in the position-control cutting stage. When the cut is relatively shallow (less than $0.1 \mathrm{~mm}$ deep), the fracture load on the rock increases with the percussion frequency; as the cut depth increases, the effect of the percussion frequency on the fracture load on the rock decreases. Figures 11(e) and 11(f) show the variation trend of the average impact-cutting load on the lunar rock simulant as a function of the percussion frequency and the cut depth. In general, the fracture load on the lunar rock simulant increases significantly with the cut depth and decreases slightly as the percussion frequency increases. The variation trend of the test results matches that of the theoretical calculation.

\subsection{Analysis and Experimental Verification of the Load} Characteristics of Rotary-Percussive Drilling with an LRCB. The load characteristics of rotary-percussive drilling with an LRCB for lunar rock simulant are investigated using a comprehensive drill characteristics test platform. The variation trends of the load on the drill bit before and after percussion is applied are compared to analyze the auxiliary effect of the impact load on the fracture of lunar rock simulant. In the test, the LRCB's percussion energy input is set to $2.6 \mathrm{~J}$. Based on the LRCB's configuration, the percussion energies gained by the different elemental blades in a percussion cycle are $0.196 \mathrm{~J}, 0.196 \mathrm{~J}, 0.182 \mathrm{~J}$, and $0.294 \mathrm{~J}$. When the coring bit rotates at $30 \mathrm{rpm}$, the penetration rate is $3 \mathrm{~mm} / \mathrm{min}$, and the percussion frequency is $20 \mathrm{~Hz}$; the variations in the LRCB drilling load before and after percussion is applied are as shown in Figure 12.

In the initial drilling stage, the LRCB penetrates at PPR of $0.1 \mathrm{~mm} / \mathrm{r}$, and the percussive mechanism is not activated (light yellow area). During this time, the drilling load gradually increases with the drilling depth, and the rotary torque and the drilling pressure stabilize at $3.71 \mathrm{Nm}$ and $482.3 \mathrm{~N}$, respectively. When the drilling depth reaches $30 \mathrm{~mm}$, the percussive mechanism is activated (light grey area). This shows that, under an impact load, the rotary torque and drilling pressure on the LRCB both decrease and eventually stabilize at $3.08 \mathrm{Nm}$ and $348.6 \mathrm{~N}$, respectively, which shows that the percussive mechanism effectively reduces the drilling load required to penetrate lunar rock simulant.

Figure 13 shows variation trend of the average drilling load of the LRCB for different PPR as the percussion frequency increases from $0 \mathrm{~Hz}$ to $20 \mathrm{~Hz}$. The bit's rotational velocity is set to $50 \mathrm{rpm}$; the PPR during drilling $(0.04-0.2 \mathrm{~mm} / \mathrm{r})$ is controlled by adjusting the penetration rate $(2-10 \mathrm{~mm} / \mathrm{min})$. When the coring bit's configuration parameters are fixed, the fluctuation in the cut depth is proportional to the PPR. Based on the fluctuation in the penetration displacement of the drilling machine detected by 




(a) Cutting force



(c) Cutting force

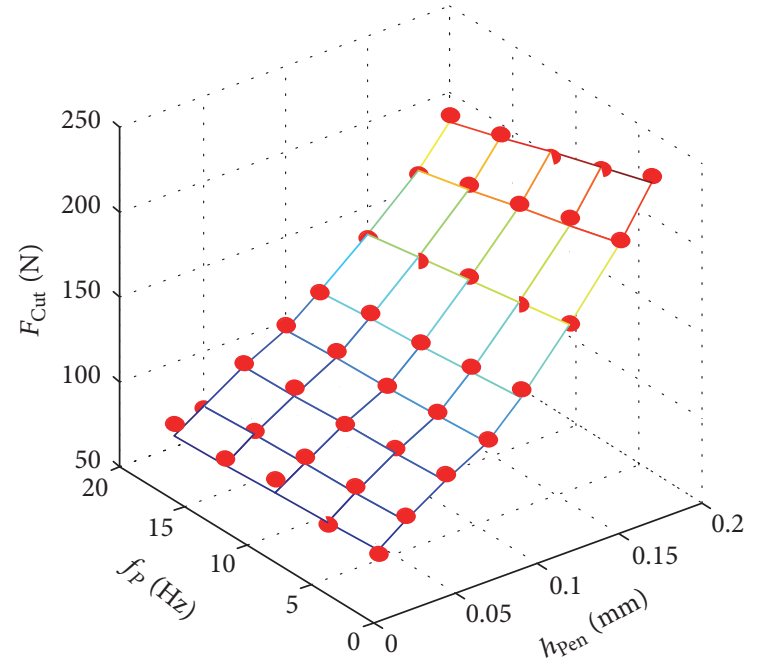

(e) Cutting force

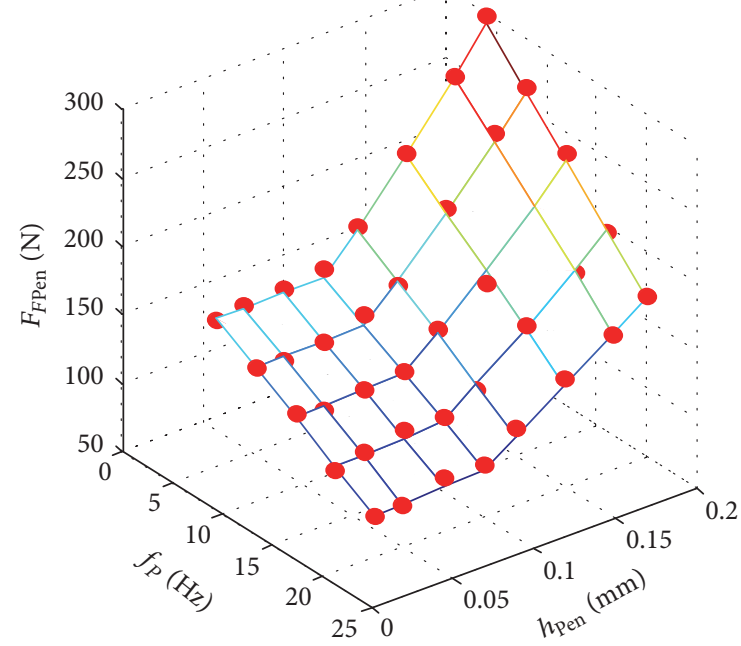

(b) Cutting pressure

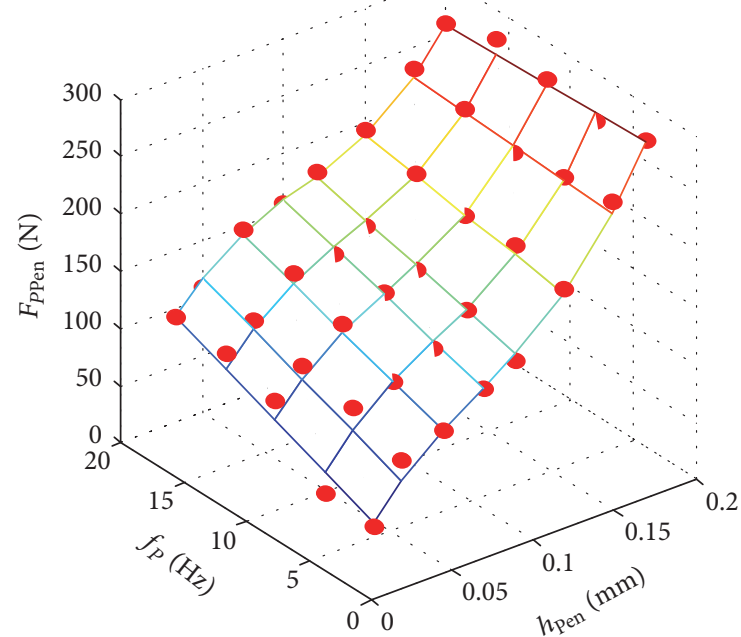

(d) Cutting pressure

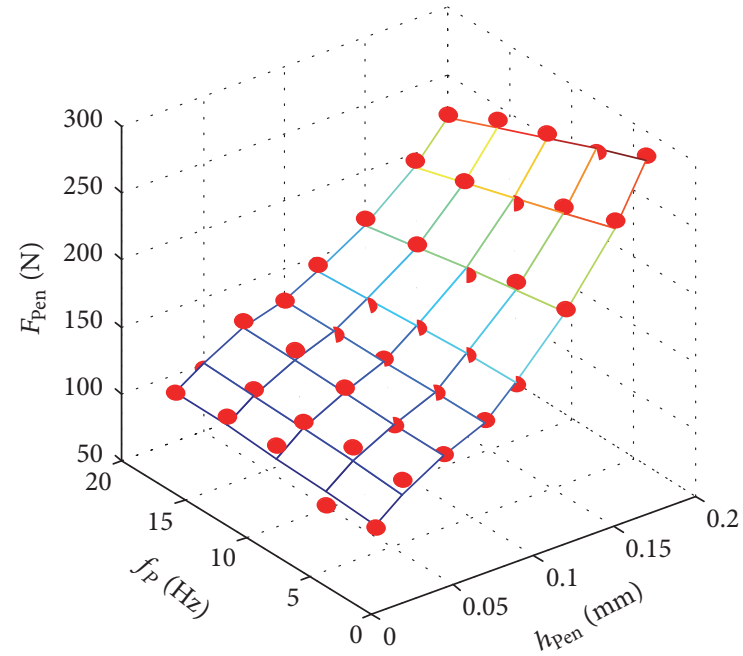

(f) Cutting pressure

FIGURE 11: Trends of the average impact-cutting load on the lunar rock simulant versus the percussion frequency and the cut depth. 


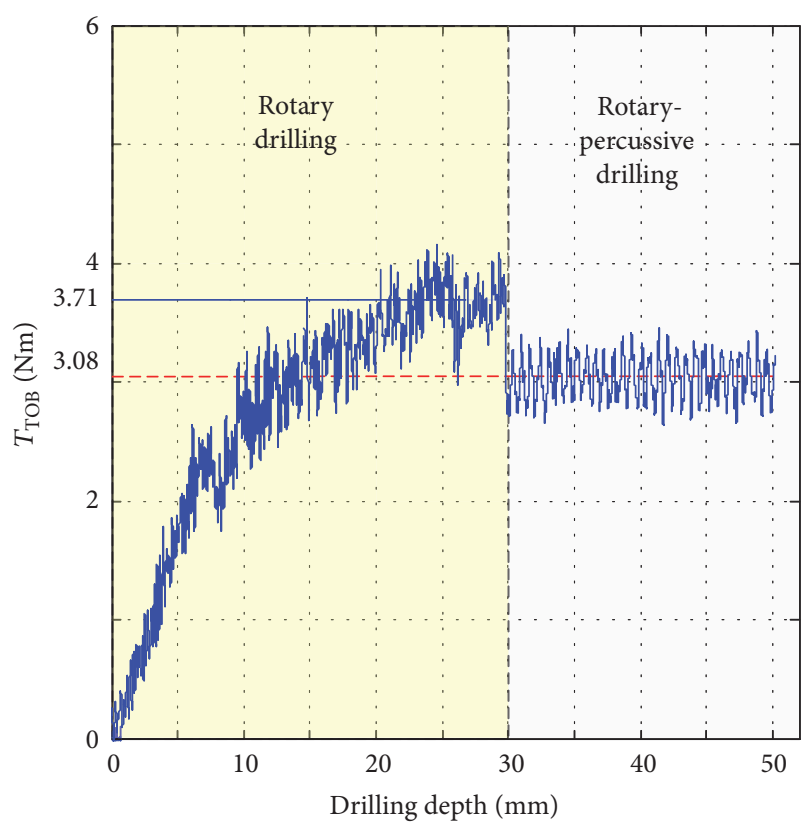

(a) Torque on bit versus drilling depth

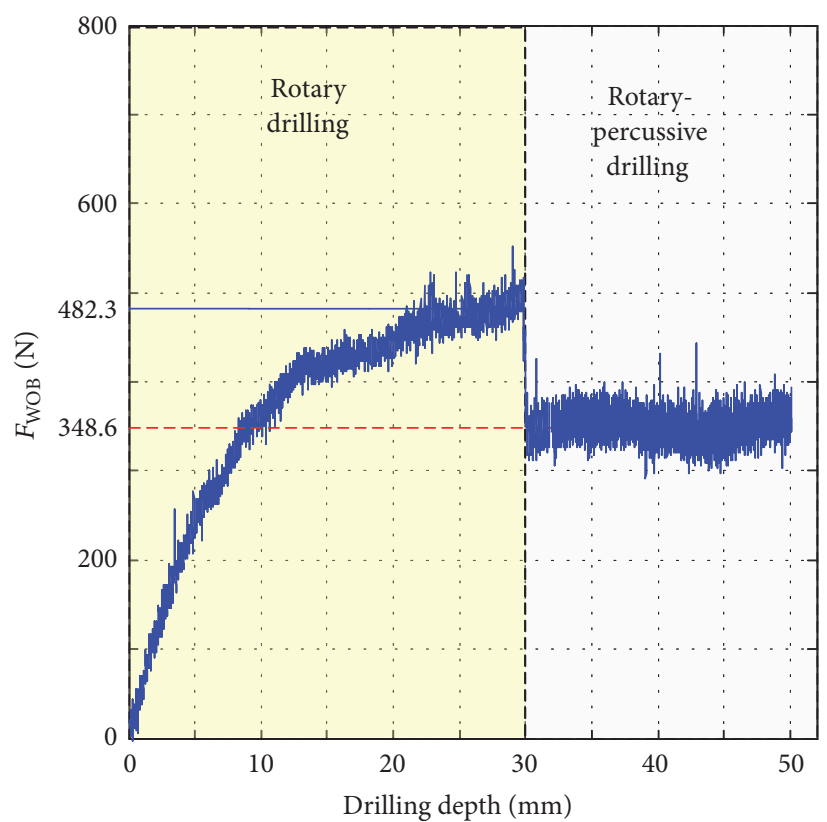

(b) Weight on bit versus drilling depth

FIGURE 12: Comparison of the LRCB drilling load before and after percussion applied.

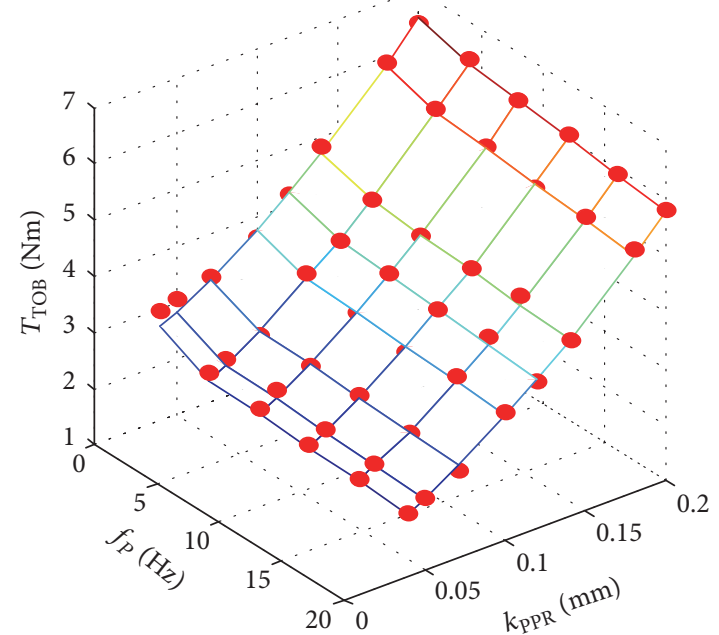

(a) $\mathrm{TOB}$

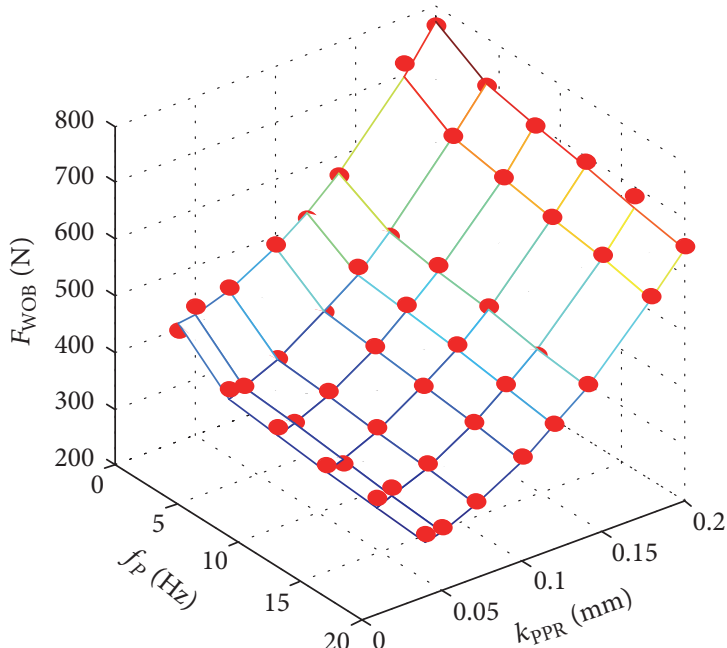

(b) WOB

FIGURE 13: Trends of the rotary-percussive drilling load of the LRCB as functions of the percussion frequency and PPR.

the magnescale sensor in a drilling cycle, a best-fit functional relationship between the fluctuation in the cut depth and the PPR of the coring bit is roughly estimated as follows:

$$
\Delta h_{P n}=\left(532 \cdot k_{\mathrm{PPR}}^{2}-3.4 \cdot k_{\mathrm{PPR}}+17.89\right) \times 10^{-4} \text {. }
$$

Figure 13 shows that, once the impact load has been introduced, the drilling load of the LRCB decreases by different amounts and decreases further as the percussion frequency increases. When the percussion frequency increases to $20 \mathrm{~Hz}$ and the PPR is $0.04 \mathrm{~mm} / \mathrm{r}$ and $0.2 \mathrm{~mm} / \mathrm{r}$, the rotary torque required to fracture the lunar rock simulant is reduced by $0.86 \mathrm{Nm}$ and $0.56 \mathrm{Nm}$, respectively; the drilling pressure required to fracture the lunar rock simulant is decreased by $85.8 \mathrm{~N}$ and $116 \mathrm{~N}$, respectively. Additionally, the variation trend of the drilling load as a function of the PPR and the percussion frequency matches the theoretical prediction.

For percussion frequency $20 \mathrm{~Hz}$ and PPR $0.1 \mathrm{~mm} / \mathrm{r}$, the variation trend of the drilling load of the LRCB is shown in Figure 14. As the rotational velocity increases, both the TOB and the WOB increase. This is because the increase in the bit's rotational velocity decreases the number of impact 


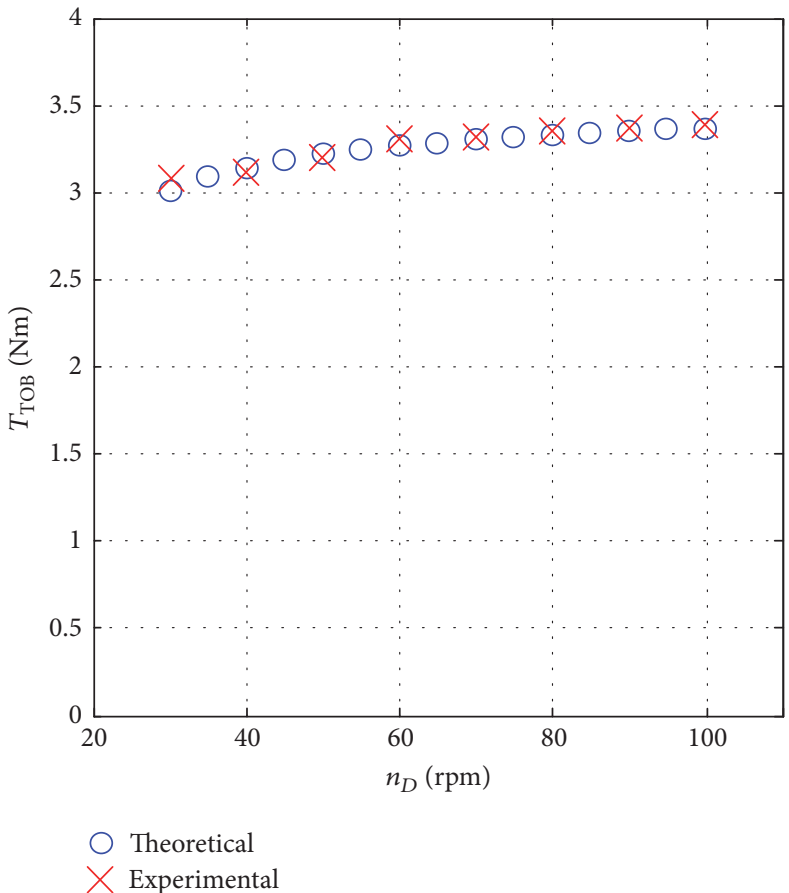

(a)

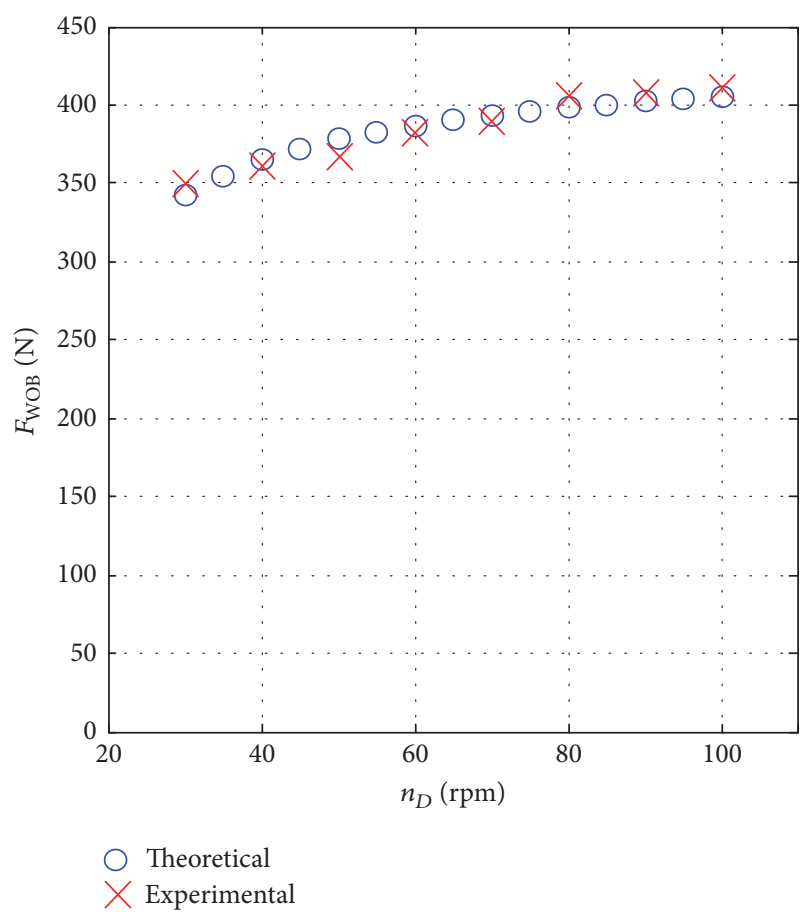

(b)

FIGURE 14: Trend of the LRCB load in rotary-percussive drilling with the increased rotational velocity and fixed PPR.

loads applied to the lunar rock simulant by the bit in each rotation cycle of the drilling process, that is, the decrease in the blow per revolution decreases the proportion of fracture due to impact-cutting coupling for the lunar rock simulant. Therefore, the drill should provide a larger TOB and a higher WOB.

\section{Conclusions}

In this paper, the process of penetrating lunar rock simulant via LRCB rotary-percussive drilling is analyzed. The following conclusions are reached:

(1) A load prediction model for lunar rock simulant penetration via LRCB rotary-percussive drilling is created. It effectively predicts the characteristics of the load on lunar rock simulant during rotarypercussive drilling within known parameter ranges (the rotational velocity is between 30 and $100 \mathrm{rpm}$; the penetration rate is between 3 and $20 \mathrm{~mm} / \mathrm{min}$; the percussion frequency is between 0 and $20 \mathrm{~Hz}$; and the single percussion energy is $2.6 \mathrm{~J}$ ) for a fixed drill configuration. These parameter ranges cover the adjustable ranges of the lunar surface sampling mechanism.

(2) The effects of the PPR, the percussion frequency, and the rotational velocity on the lunar rock simulant's drilling load are determined. The PPR is the primary parameter influencing the drilling load. When the PPR is fixed, introducing an impact load effectively decreases the drilling load on the lunar rock simulant. Additionally, the drilling load is inversely proportional to the percussion frequency. When the percussion frequency reaches its upper limit, reducing the rotational velocity increases the blow per revolution, improves the bit's efficiency at penetrating and fracturing rock in a cycle, and further decreases the drilling load on the rock.

To simplify the model, impact load loss induced by the bit's configuration is not considered in this paper. A relevant investigation will be conducted in subsequent research.

\section{Conflicts of Interest}

The authors declare that they have no conflicts of interest.

\section{Acknowledgments}

This work was financially supported by the technology research projects of the China lunar exploration (Project no. TY3Q20110005), the National Natural Science Foundation of China (Grant nos. 51575122 and 51575123), and the SelfPlanned Task (no. SKLRS201616B) of State Key Laboratory of Robotics and System (HIT).

\section{References}

[1] Y. Bar-Cohen and K. Zacny, "Drilling in Extreme Environments," in Chapter Extraterrestrial Drilling and Excavation, pp. 347-546, VILEY-VCH, 2008. 
[2] B. Huang, Z. Jiang, P. Lin, and D. Ling, "Research on impact process of lander footpad against simulant lunar soils," Shock and Vibration, vol. 2015, Article ID 658386, 24 pages, 2015.

[3] X. Shi, Z. Deng, Q. Quan, D. Tang, X. Hou, and S. Jiang, "Development of a drilling and coring test-bed for lunar subsurface exploration and preliminary experiments," Chinese Journal of Mechanical Engineering (English Edition), vol. 27, no. 4, pp. 673-682, 2014.

[4] J. Allton, Catalog of Apollo Lunar Surface Geological Sampling Tools and Containers, NASA, 1989.

[5] K. Zacny, J. Wilson, P. Chu, and J. Craft, "Prototype rotary percussive drill for the Mars sample return mission," in proceeding of the 2011 IEEE Aerospace Conference, AERO '11, 9 pages, Montana, MT, USA, March 2011.

[6] K. Klein, M. Badescu, N. Haddad, L. Shiraishi, and P. Walkemeyer, "Development and testing of a rotary percussive Sample Acquisition Tool," in proceeding of the 2012 IEEE Aerospace Conference, Montana, MT, USA, March 2012.

[7] Y. Tian, Z. Deng, D. Tang, S. Jiang, and X. Hou, "Structure parameters optimization and simulation experiment of auger in lunar soil drill-sampling device," Journal of Mechanical Engineering, vol. 48, no. 23, pp. 10-15, 2012.

[8] Z. Y. Ouyang, "Scientific objectives of chinese lunar exploration project and development strategy," Advance in Earth Sciences, vol. 19, pp. 351-358, 2004.

[9] L. Barsukov, "Preliminary data for the regolith core brought to Earth by the automatic lunar station luna 24," in proceeding of the 8th Lunar Planetary Science Conference, pp. 3303-3318, 1977.

[10] Y. Tian, D. Tang, Z. Deng, S. Jiang, and Q. Quan, “Drilling power consumption and soil conveying volume performances of lunar sampling auger," Chinese Journal of Mechanical Engineering (English Edition), vol. 28, no. 3, pp. 451-459, 2015.

[11] S.-M. E. Jalali and M. Zare Naghadehi, "Development of a new laboratory apparatus for the examination of the rotarypercussive penetration in tunnel boring machines," Tunnelling and Underground Space Technology, vol. 33, pp. 88-97, 2013.

[12] K. Hashiba, K. Fukui, Y. Z. Liang, M. Koizumi, and T. Matsuda, "Force-penetration curves of a button bit generated during impact penetration into rock," International Journal of Impact Engineering, vol. 85, pp. 45-56, 2015.

[13] T. Saksala, D. Gomon, M. Hokka, and V.-T. Kuokkala, "Numerical and experimental study of percussive drilling with a triplebutton bit on Kuru granite," International Journal of Impact Engineering, vol. 72, pp. 56-66, 2014.

[14] T. Saksala, "Numerical study of the influence of hydrostatic and confining pressure on percussive drilling of hard rock," Computers and Geotechnics, vol. 76, pp. 120-128, 2016.

[15] T. Saksala, M. Hokka, V.-T. Kuokkala, and J. Mäkinen, "Numerical modeling and experimentation of dynamic Brazilian disc test on Kuru granite," International Journal of Rock Mechanics \& Mining Sciences, vol. 59, pp. 128-138, 2013.

[16] J. Tian, C. Wu, L. Yang, Z. Yang, G. Liu, and C. Yuan, "Mathematical Modeling and Analysis of Drill String Longitudinal Vibration with Lateral Inertia Effect," Shock and Vibration, vol. 2016, Article ID 6281264, 8 pages, 2016.

[17] L. J. Dong and X. B. Li, "A microseismic/acoustic emission source location method using arrival times of PS waves for unknown velocity system," International Journal of Distributed Sensor Networks, vol. 2013, Article ID 307489, 8 pages, 2013.

[18] L. Dong, X. Li, and G. Xie, "Nonlinear methodologies for identifying seismic event and nuclear explosion using random forest, support vector machine, and naive Bayes classification," Abstract and Applied Analysis, vol. 2014, Article ID 459137, 8 pages, 2014.

[19] L.-J. Dong, J. Wesseloo, Y. Potvin, and X.-B. Li, “Discriminant models of blasts and seismic events in mine seismology," International Journal of Rock Mechanics \& Mining Sciences, vol. 86, pp. 282-291, 2016.

[20] P. Li, S. Jiang, D. Tang et al., "Design and testing of coring bits on drilling lunar rock simulant," Advances in Space Research, vol. 59, pp. 1057-1076, 2017.

[21] D. Zhao, D. Tang, X. Hou, S. Jiang, and Z. Deng, "Soil chip convey of lunar subsurface auger drill," Advances in Space Research, vol. 57, no. 10, pp. 2196-2203, 2016.

[22] D. Zhao, S. Jiang, D. Tang et al., "Structure design of lunar subsurface sampling drill," Journal of Jilin University (Engineering and Technology Edition), vol. 46, pp. 1-10, 2016.

[23] P. Li, S. Jiang, D. Tang et al., "A PFC ${ }^{3 D}$-based numerical simulation of cutting load for lunar rock simulant and experimental validation," Advances in Space Research, In press, 2017.

[24] Q. Quan, P. Li, S. Jiang et al., "Development of a rotarypercussive drilling mechanism (RPDM)," in proceeding of the 2012 IEEE International Conference on Robotics and Biomimetics, ROBIO '12, pp. 950-955, Guangzhou, China, December 2012.

[25] D. Jie, P. Li, Q. Quan et al., "Optimization of percussive mechanism in rotary-percussion drill for lunar exploration," in proceeding of the 2013 IEEE International Conference on Robotics and Biomimetics, ROBIO '13, pp. 2130-2135, Shenzhen, China, December 2013.

[26] I. Argatov and M. Jokinen, "Longitudinal elastic stress impulse induced by impact through a spring-dashpot system: optimization and inverse problems for the spring stiffness," International Journal of Solids and Structures, vol. 50, no. 24, pp. 3960-3966, 2013.

[27] D. Tang, P. Li, S. Jiang, Q. Quan, X. Hou, and Z. Deng, "Numerical simulation of lunar rock simulant cutting load based on discrete element modeling and experimental validation," Journal of Mechanical Engineering, vol. 52, no. 15, pp. 192203, 2016.

[28] P. Li, S. Jiang, Q. Quan, D. Tang, X. Hou, and Z. Deng, "A drilling tactic to tackle indeterminable environment in lunar regolith sampling," in proceeding of the IEEE International Conference on Robotics and Biomimetics, IEEE-ROBIO '15, pp. 2347-2352, Zhuhai, China, December 2015. 


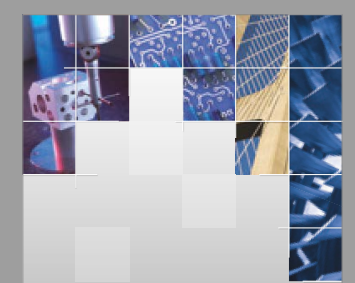

\section{Enfincering}
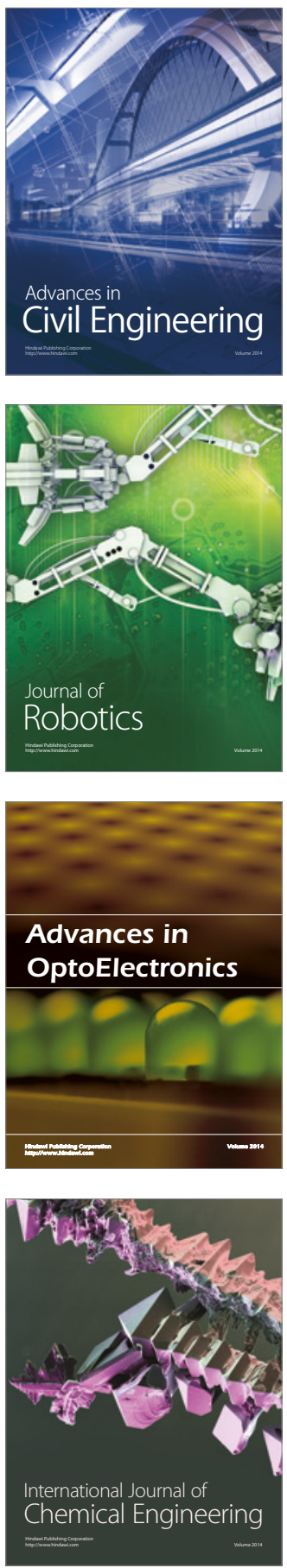

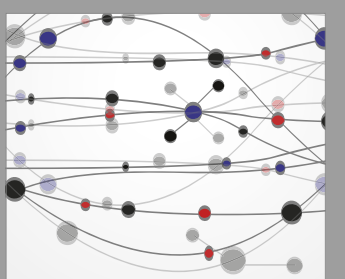

The Scientific World Journal

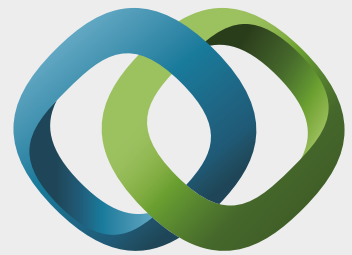

\section{Hindawi}

Submit your manuscripts at

https://www.hindawi.com
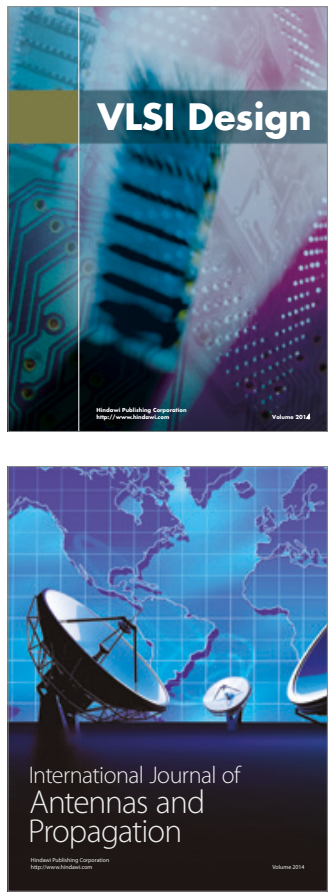

\section{Rotating}

Machinery
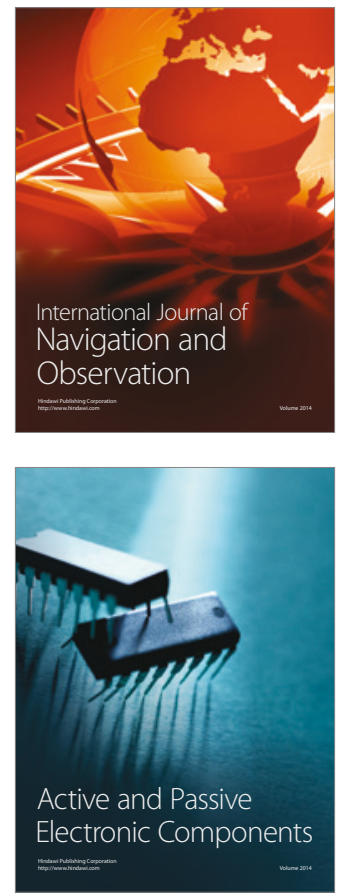
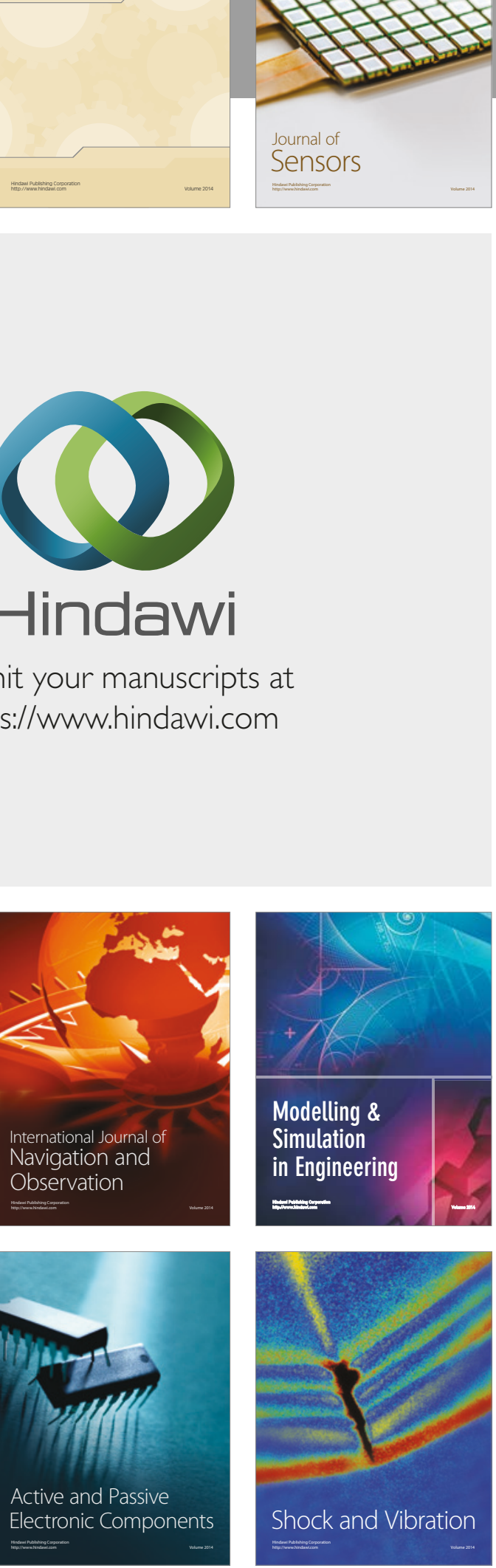


Distributed

Journal of

Control Science

and Engineering
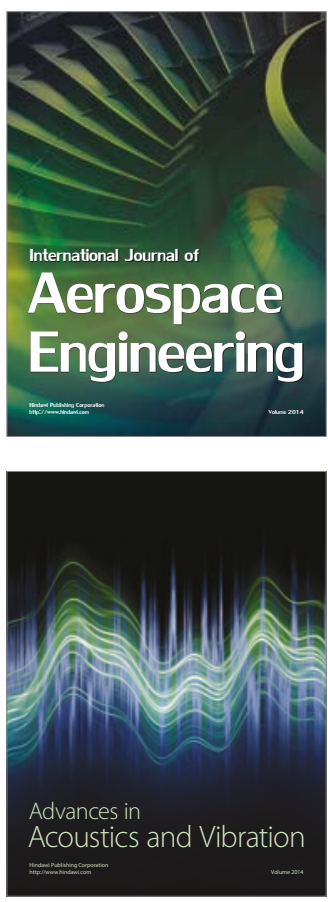

Sensor Networks 